\title{
FUNDAMENTOS JURÍDICOS PARA AS CONTRATAÇÕES SUSTENTÁVEIS DA ADMINISTRAÇÃO PÚBLICA
}

\section{Dilene Soares Tavares dos Anjos ${ }^{1}$}

A Constituição Federal de 1988 trouxe como dever do Estado a proteção ao meio ambiente (art. 225, caput), exigindo do Poder Público (inciso IV), o estudo prévio de impacto ambiental para toda obra ou atividade causadora de significativa degradação do meio ambiente.

A Emenda Constitucional n. 42, de 19 de dezembro de 2003, alterou o inciso VI do art. 170, incorporando a "defesa do meio ambiente, inclusive mediante tratamento diferenciado conforme o impacto ambiental dos produtos e serviços e de seus processos de elaboração e prestação" ao rol dos princípios gerais da atividade econômica.

Por seu turno, a Lei n. 8.666, de 21 de junho de 1993, dispôs, em seu art. 12, VII, que o impacto ambiental seria requisito básico a ser considerado na elaboração de projetos básicos e executivos de obras e serviços.

Com redação dada pela Lei n. 12.349, de 15 de dezembro de 2010, o art. $3^{\circ}$ da Lei n. 8.666/1993 estabeleceu que a promoção do desenvolvimento nacional sustentável é um dos três fundamentos das licitações públicas, juntamente com a isonomia e a seleção da proposta mais vantajosa para a Administração.

Vários outros instrumentos legais foram sendo editados, tratando de critérios socioambientais a serem considerados nas licitações e contratações públicas, como a Lei n. 10.257, de 10.7.2001, a Lei n. 12.187, de 29.12.2009, a Lei n. 12.305, de 2.8.2010 e a Lei n. 12.349, de 15.12.2010.

O Decreto n. 2.783, de 17 de setembro de 1998, proíbe que a Administração Pública Federal direta, autárquica e funcional adquira produtos ou equipamentos que contenham ou façam uso de substâncias que destroem a camada de ozônio.

Por sua vez, o Decreto n. 5.940, de 25 de outubro de 2006, disciplina a separação dos resíduos recicláveis descartados por aqueles órgãos e a sua destinação às associações e cooperativas dos catadores de materiais recicláveis.

Com vistas à promoção do desenvolvimento nacional sustentável, foram editados os Decretos n. 7.756, de 14 de junho de 2012, e 7.767, de 
27 de junho de 2012, que estabelecem margem de preferência nas licitações para a aquisição de produtos manufaturados nacionais (o primeiro para aquisição de confecções, calçados e artefatos e o segundo para aquisição de produtos médicos).

Regulamentando o art. $3^{\circ}$ da Lei n. 8.666/1993, foi editado o Decreto n. 7.746, de 5 de junho de 2012, o qual estabeleceu critérios, práticas e diretrizes para a promoção do desenvolvimento nacional sustentável nas contratações realizadas pela Administração Pública Federal e instituiu a Comissão Interministerial de Sustentabilidade na Administração Pública - CISAP.

Referido Decreto, de observância cogente por todos os órgãos públicos, traz, em seu art. $4^{\circ}$, as diretrizes de sustentabilidade, a saber:

I - menor impacto sobre recursos naturais como flora, fauna, ar, solo e água;

II - preferência para materiais, tecnologias e matérias-primas de origem local;

III - maior eficiência na utilização de recursos naturais como água e energia;

IV - maior geração de empregos, preferencialmente com mão de obra local;

$\checkmark$ - maior vida útil e menor custo de manutenção do bem e da obra;

VI - uso de inovações que reduzam a pressão sobre recursos naturais; e

VII - origem ambientalmente regular dos recursos naturais utilizados nos bens, serviços e obras.

Em seu art. 16, disciplina a implementação de Planos de Gestão de Logística Sustentável, os quais deverão prever, no mínimo:

I - atualização do inventário de bens e materiais do órgão e identificação de similares de menor impacto ambiental para substituição;

II - práticas de sustentabilidade e de racionalização do uso de materiais e serviços;

III - responsabilidades, metodologia de implementação e avaliação do plano; e

IV - ações de divulgação, conscientização e capacitação.

Trata-se, pois, de uma tendência de gerar políticas em que os aspectos ambientais sejam considerados, visando reduzir impactos sobre a saúde humana, o meio ambiente e os direitos humanos. 
O Conselho Nacional de Justiça (CNJ), por meio da Recomendação n. 11, de 22 de maio de 2007, recomendou aos Tribunais relacionados nos incisos II a VII do art. 92 da Constituição Federal de 1988 - dentre os quais se encontram os Tribunais Eleitorais - que adotassem políticas públicas visando à formação e recuperação de um ambiente ecologicamente equilibrado, além da conscientização dos próprios servidores e jurisdicionados sobre a necessidade de efetiva proteção ao meio ambiente, bem como instituíssem comissões ambientais para o planejamento, elaboração e acompanhamento de medidas, com fixação de metas anuais, visando à correta preservação e recuperação do meio ambiente.

No corpo da norma, sinalizou alguns exemplos do que considerou viável naquele momento:

a) utilização de papel reciclado e não clorado nos impressos do Poder Judiciário, sejam de natureza administrativa ou processual;

b) instituição da coleta seletiva de resíduos, destinando recipientes individuais para plástico, papel, metal e vidro, e a ulterior doação do material coletado a entidades assistenciais que se responsabilizem pela correta utilização do material para a devida reciclagem;

c) aquisição de impressoras que imprimam, automaticamente, em frente e verso;

d) aquisição de bens e materiais de consumo que levem em consideração o tripé básico da sustentabilidade: ambientalmente correto, socialmente justo e economicamente viável;

e) utilização sustentável da energia e dos combustíveis; e ente.

f) utilização de edifícios com observância da proteção ao meio ambi-

Por sua vez, o Tribunal de Contas da União, no Acórdão n. 1.752/2011 - Plenário, examinou as ações de sustentabilidade e eficiência adotadas pela Administração Pública Federal visando ao uso racional de energia elétrica, água e papel.

Do Acórdão, extraem-se indicações de medidas consideradas eficientes pelo Tribunal de Contas da União para a defesa do meio ambiente:

- aquisição de materiais e equipamentos com selo Procel "A";

- manutenção preventiva da rede elétrica; 
- instalação de torneiras com aeradores e fechamento automático e bacias sanitárias de baixo consumo;

- vistorias permanentes nas instalações hidráulicas para detecção de vazamentos;

- padronização de impressão em modo econômico e/ou frente e verso;

- reutilização de papel usado para confecção de blocos de rascunho;

- utilização de papel não clorado ou papel reciclado;

- campanhas de conscientização dos usuários;

- utilização de informativos e cartazes educativos para sensibilizar servidores e funcionários terceirizados quanto ao uso racional de energia elétrica, água e papel;

- divulgação interna do consumo atual e das metas de redução para os funcionários;

- descarte de materiais recicláveis, destinando-os a associações e cooperativas de catadores;

- uso sustentável do sistema de ar condicionado, com (1) a desobstrução das grelhas de circulação de ar, manutenção de portas e janelas fechadas com o equipamento ligado e desligamento do aparelho em ambientes desocupados por longo período de tempo e (2) controle de temperatura por ambiente, isolamento térmico de tubulações e tanques de serviços e escolha de sistema que leve em consideração os custos de manutenção, operação e consumo de energia;

- uso de luminárias de alta refletância, com refletor de alumínio anodizado e redução de reatores;

- colocação de interruptores em cada sala, com envolvimento do serviço de vigilância na verificação do desligamento das luzes de salas e de disjuntores;

- utilização de sensores de presença em locais de pouco trânsito de pessoas; 
- orientação aos servidores para que desliguem computadores e impressoras ao final do expediente, uma vez que, quando deixados em modo stand-by, consomem energia desnecessariamente;

- verificação da adequação da faixa de consumo e da demanda contratada junto à Concessionária, de forma a averiguar se se está contratando a demanda de energia mais econômica para o perfil de consumo;

- nas construções de edificações, além dos itens mencionados acima, verificar a orientação adequada das fachadas, o uso de material de elevada resistência térmica, a opção por cores claras e a adoção de sistema de aproveitamento de água da chuva para limpeza de áreas externas e irrigação de jardins;

- utilização de scanners para copiar documentos, substituindo a reprografia;

- utilização de correio eletrônico para envio de comunicações;

- uso de contracheque eletrônico e formulários eletrônicos.

Outrossim, afirmou a Corte de Contas que as instituições devem se preocupar em elaborar um diagnóstico para avaliar o perfil de consumo e os potenciais de redução existentes em suas instalações prediais e que, somente a partir desse diagnóstico, é possível caracterizar hábitos e vícios de desperdício, mapear ações corretivas e estudar alternativas para substituição de equipamentos convencionais por outros mais eficientes. Sugere que os órgãos comparem o consumo atual de água com o histórico da própria instituição ao longo dos últimos anos, a fim de verificar alguma variação brusca, a qual pode ser reflexo de vazamento de água, e de traçar metas de redução do consumo.

Orienta, ainda, que as ações visando ao uso racional de recursos naturais sejam formalizadas, de modo a garantir sua continuidade como política institucional da Administração, designando um responsável para implementar e controlar as ações de uso racional e sustentabilidade.

Especificamente sobre as compras sustentáveis, a Corte de Contas assevera que os gestores, ao não levarem em conta o ciclo de vida de um produto na análise da economicidade da aquisição, correm o risco de não adquirir produto em condição mais econômica para a Administração, já que os custos de instalação e de manutenção podem tornar essa opção mais onerosa que seus similares, a ponto de se configurar prejuízo aos cofres públicos no decurso de sua vida útil. 
Por fim, importante transcrever excerto do Voto do Ministro Relator, André Luís de Carvalho:

A proposta em exame ecoa de modo significativo nos princípios enumerados no art. 37 da Constituição Federal, a saber: (i) a observância de práticas de sustentabilidade em conformidade com os normativos legais e infralegais existentes reflete o respeito ao princípio da legalidade, (ii) a abstenção da utilização com fins pessoais de recursos públicos chama atenção para o devido respeito aos princípios da moralidade e da impessoalidade, (iii) a transparência conferida à forma de utilização dos recursos e à disseminação das boas práticas, por seu turno, aponta no sentido da devida publicidade dos atos administrativos e, por fim, (iv) o uso racional desses recursos prestigia o elemento faltante, a eficiência, elevada à condição de princípio de estatura constitucional pela reforma administrativa promovida com a Emenda Constitucional $n^{\circ} 19$, de 4 de junho de 1998.

Da leitura do Acórdão TCU n. 1.752/2011 - Plenário, verifica-se que é recomendável que, primeiramente, o órgão estabeleça os parâmetros, as diretrizes, as metas e o interesse da Administração na implementação das compras públicas sustentáveis.

Na sequência, as experiências internacionais demonstram que a forma mais simples de dar início ao processo de compras públicas sustentáveis é a inserção dos critérios de sustentabilidade na definição do produto, os quais devem ser devida e tecnicamente justificados pelo setor requisitante.

A fim de tornar possível esse processo, é aconselhável que sejam incluídos nos Programas de Capacitação e Desenvolvimento dos órgãos, cursos destinados a instruir os servidores envolvidos nos processos de compras e os demais servidores, a fim de sensibilizá-los e conscientizálos sobre o tema.

Acerca da sustentabilidade, frisa-se que alguns produtos podem ser considerados sustentáveis por gerarem menos perdas, por serem recicláveis ou mais duráveis; outros, por conterem menos substâncias prejudiciais ou tóxicas ou porque o processo de sua geração consome menos energia.

Impende ressaltar que, previamente à definição do objeto, o setor requisitante deve verificar, mediante pesquisa de mercado: (1) as alternativas disponíveis; (2) a vantajosidade na aquisição do objeto para a Administração, levando-se em consideração o custo e o impacto no meio 
ambiente; (3) se há vários produtos que atendem ao interesse da Administração, para que não se configure direcionamento.

Ademais, no intuito de se inserirem critérios ambientais nos editais licitatórios, deve-se analisar se é possível julgar as propostas de forma objetiva, utilizando-se de parâmetros objetivos, e sem frustrar a competitividade.

Outras duas maneiras de realizar compras sustentáveis são a exigência de determinados requisitos de habilitação e a imposição de obrigações às empresas contratadas.

As exigências de documentação, contudo, praticamente só podem constar das licitações do tipo melhor técnica ou técnica e preço, por meio de pontuações, uma vez que o Tribunal de Contas da União tem reiteradamente se manifestado que não se podem inabilitar empresas que não possuam as Certificações e ISOs - já que a Lei de Licitações traz, em seu art. 30 , rol exaustivo de documentos relativos à qualificação técnica -, ou desclassificar propostas, em virtude de os produtos não possuírem selos de qualidade, em função de restrição da competitividade.

A Corte de Contas também não admite que os atos convocatórios prevejam cláusulas desnecessárias ou inadequadas. Por outro lado, entende que a verificação de qualificação técnica não ofende o princípio da isonomia, desde que as exigências sejam indispensáveis à garantia do cumprimento das obrigações.

Assim, percebe-se que, apesar de o tema das contratações sustentáveis estar embasado em premissas constitucionais, legais e infralegais, seu processo ainda está em fase de amadurecimento, o que sugere que sua adoção seja feita com cautela e responsabilidade e que seja precedido de normatização interna própria, em que sejam fixados parâmetros, diretrizes e metas na implementação das compras públicas sustentáveis.

\section{Notas}

${ }^{1}$ Analista Judiciário do TRESC. Bacharel em Letras-Tradução/Inglês pela UnB e em Direito pela Univali. Especialista em Direito Civil e em Direito Administrativo pela Unisul. 